\title{
An Alternative Approach to the Rationalization of the Production Process Using Simulation Methods
}

\author{
Darina Dupláková, Monika Töröková, Ján Duplák, Jozef Török \\ Technical University of Kosice, Faculty of technologies with a seat in Presov, \\ Bayerova 1, 08001 Prešov, Slovakia
}

\begin{abstract}
Simulation in a production process represents the realization of processes in time and space. In manufacturing, the current trend is towards the implementation and expansion of various types of systems in many industrial enterprises. This effort is supported by requirements to increase reliability, eliminate production times and costs, as well as meet operational schedules. The presented article is focused on the possibilities of alternative approaches to the rationalization of production processes using simulation methods. The introduction of this article is devoted to the issue of simulations in general with a brief overview of historical development and classification of simulation tools. The second part of the article describes the tools used for comparative rationalization, which forms the core of the presented article. The conclusion summarizes the findings of the study.
\end{abstract}

Keywords - simulation, rationalization, production process.

\section{Introduction}

Systems for production processes and their tools for material flow simulations are designed to analyse the

DOI: $10.18421 /$ SAR41-01

https://doi.org/10.18421/SAR41-01

Corresponding author: Darina Duplakova,

Technical Univesrity of Kosice, Faculty of Manufacturing Technologies with a seat Presov, Bayerova 1, 08001 Presov, Slovakia.

Email: darina.duplakova@tuke.sk

Received: 16 February 2021.

Revised: 08 March 2021.

Accepted: 15 March 2021.

Published: 22 March 2021

(c) BY-NC-ND 2021 Darina Duplakova et al; published by UIKTEN. This work is licensed under the Creative Commons Attribution-NonCommercial-NoDerivs 3.0 License.

The article is published with Open Access at www.sarjournal.com behaviour of complex systems that cannot be solved by other methods. Simulation is the only way to describe the behaviour of even very complex processes with consideration of random phenomena and all the essential external and internal connections [1]. These systems include tools for simulation model design, including 3D visualization of products, machines, devices, and workers, as well as analytical tools to verify the performance and throughput of production lines for a given period [2], [3].

Simulation tools use their programming language to solve complex logical problems and functions. The search for the optimal parameter setting for the required outputs is performed automatically. For a clear display of the production process, the systems are equipped with a dynamic display of the simulation model; they also provide information for individual machines and the entire simulated production [5]. Simulation tools can be classified from several aspects. Important classifications can be included by classifying the applicability and elaboration of details of simulation tools for macroscopic, mesoscopic, and microscopic simulations [6].

- Macroscopic simulation tools are primarily based on deterministic relationships between speed, and material flow intensity and they are designed to model larger production systems because they also provide the most accurate results. Their identification level is generally lower and describes the overall behaviour of production in the modelled areas. Macroscopic simulation models are generally suitable for long-term strategic planning. Macroscopic simulation tools are less computer-intensive than others, although in today's world there are already many technologies available online and there is no need to purchase them permanently.

- Mesoscopic simulation tools combine the properties of macroscopic and microscopic simulation tools. These tools can be used, for example, to model applications and impacts on manufacturing systems where macroscopic simulation cannot be used due to insufficient 


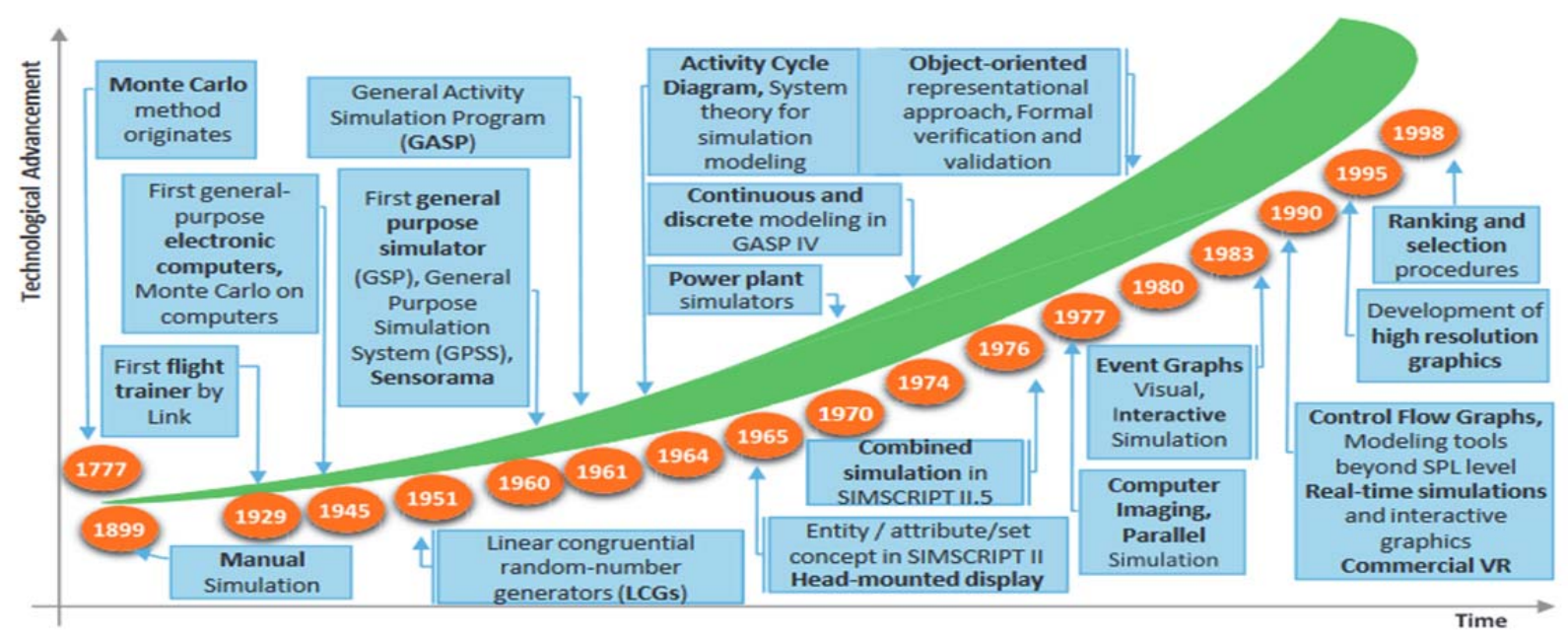

Figure 1. The historical framework of simulation [4]

detail. Mesoscopic simulation is used in practice minimally.

- Simulation tools at the microscopic level provide the most detailed information and an overview of the possibilities and rationalization of production processes.

One of the partial goals of companies is currently the optimization of internal company processes. It usually focuses on production and logistics processes, methods of production management and setting the material flow, which is related to the change of layout, i.e., the appropriate location of workplaces [7], [8]. Optimization and rationalization processes involve several operations and methods, and their success varies due to many factors. The success of rationalization measures is mainly because all activities in the company interact and it is often not possible to predict in advance what the resulting impact of the proposed changes is. One of the ways to increase the probability of making the right decisions in the company several times is to implement discrete simulation models [9], [10]. Relatively problematic and often very time consuming for computational time and powerful computers is the need to perform many simulation experiments in the case of solving larger simulation tasks. Many times, the task is practically impossible due to the high demands on computing time. For example, solving the problem of optimally setting five parameters, each of which can only take ten values, requires a total of 105 experiments, which would, for example, require a computation time of about seventy days for one experiment lasting one minute. Therefore, it is always necessary to perform as few simulation experiments as possible while maintaining an acceptable level of accuracy of the results. For these purposes, it is possible to use optimization tools, which are usually part of simulation tools and combine several production operations into the production process.

\section{Material and Methods}

During the creation of simulation models, it is necessary to correctly determine the problem, which can be subsequently verified by a flow chart of the simulation. The flow chart is composed of several decision blocks, while its final part relates to the analysis and outputs of a specific simulation [11].

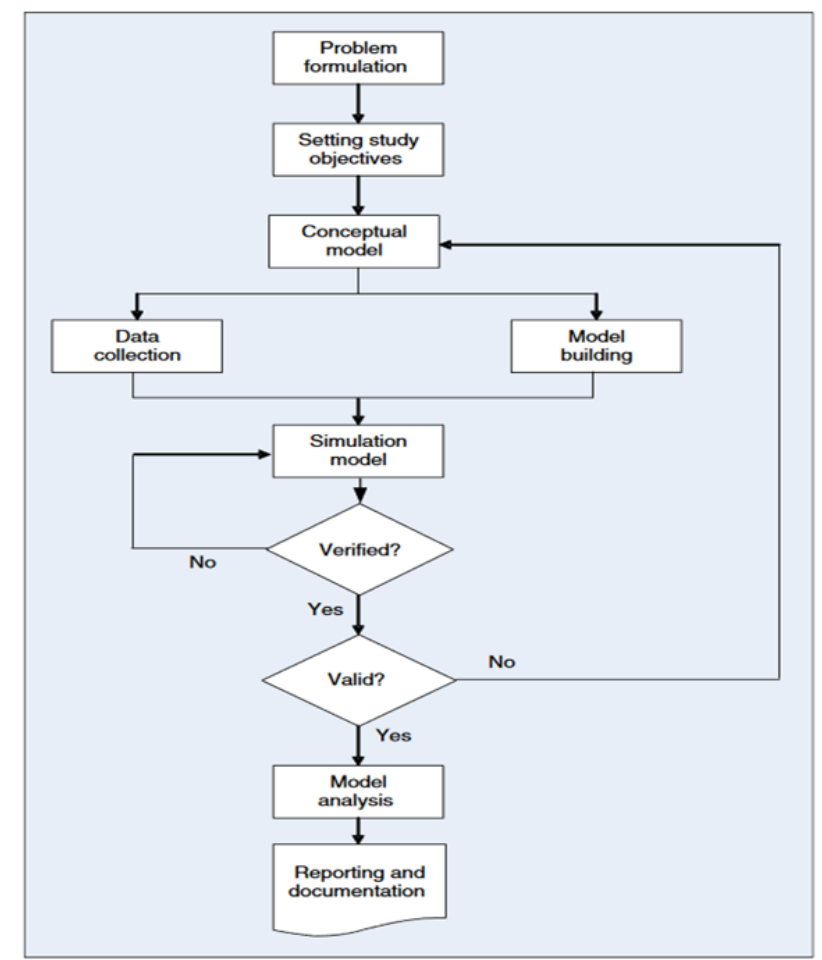

Figure 2. Flow chart of simulation [11]

As part of the comparative rationalization, two highly frequented simulation tools, Tecnomatix Plant Simulation and Witness, were chosen.

Tecnomatix is used to model production systems, processes, material flow and logistics operations. The virtual model created in this way is used for simulation, analysis, visualization, creation of statistical operations and optimization according to 
the required criteria. The software is part of PLM (Product Lifecycle Management Software), but it is also a stand-alone unit, focusing on ongoing production and its rationalization.
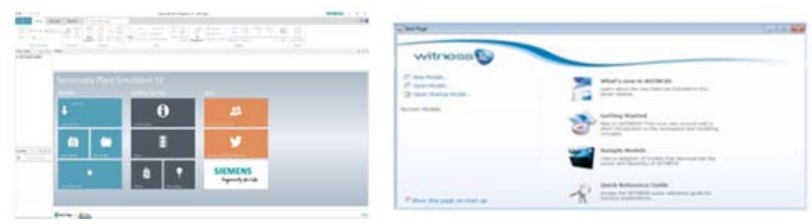

Figure 3. Tecnomatix Plant Simulation (left) and Witness (right)

Witness Horizon is a flexible simulation tool that allows workers to quickly develop feature-rich models. The simulation tool enables dynamic data visualization and provides testing of a virtual environment. This simulation software can be used especially for the optimization of production batches, optimization of production processes, optimization of capital investments, optimization of logistics processes and services, implementation of modern management methods, capacity planning, identification of production bottlenecks, production cell deployment, quality monitoring, and reducing production.

\section{Comparative Rationalization with Simulation Tools}

The model situation for the needs of comparison was created in the two above-mentioned tools designed for simulation of production processes and systems. To create the model, it was necessary to define the basic production parameters, determine the material flow and ensure interconnectivity. The production model consists of seven workplaces to which the material is transported from the entrance warehouse. The finished product destined for shipping is transported to the output warehouse.

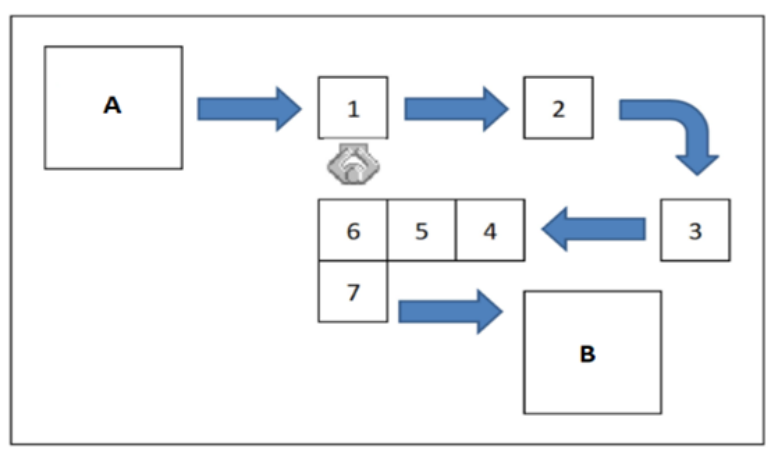

Figure 4. Diagram of material flow

The definition of production parameters was identical in both cases. The production time for each operation and the time of transport between workplaces were determined for the input data (Table $1)$.

\section{Table 1. Input data of simulation}

\begin{tabular}{|l|c|c|}
\hline Production parameters & $\begin{array}{c}\text { Producti } \\
\text { on time }\end{array}$ & $\begin{array}{c}\text { Time of } \\
\text { transport }\end{array}$ \\
\hline Warehouse - input A & - & 5 \\
\hline Workplace No. 1 & 27 & 4 \\
\hline Workplace No. 2 & 18 & 5 \\
\hline Workplace No. 3 & 9 & 4 \\
\hline Workplace No. 4 & 11 & 1.5 \\
\hline Workplace No. 5 & 13 & 1.5 \\
\hline Workplace No. 6 & 7 & 1.5 \\
\hline Workplace No. 7 & 9 & 4 \\
\hline Warehouse - output B & - & \\
\hline
\end{tabular}

In the first phase, it is necessary to create all entities in the work environment, with the subsequent determination of the input parameters of the model.

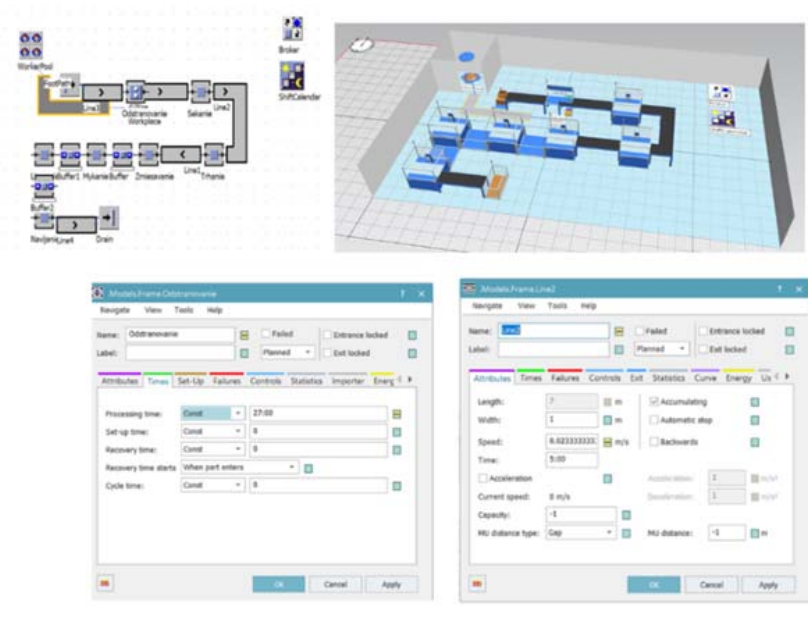

Figure 5. Creation of simulation model - Tecnomatix Plant

The appropriate model design makes it possible to predict the behaviour of the production system as a whole and its partial components. Based on the performed simulations, the value of portion, count of machined work pieces, and time of production process was determined after basic parametric settings.

\begin{tabular}{|l|r|r|r|r|r|}
\hline \multicolumn{1}{|c|}{ Object } & \multicolumn{2}{c}{ Portion Count } & \multicolumn{1}{c|}{ Sum } & \multicolumn{2}{c|}{ Mean Value Standard Deviation } \\
\hline Sekanie & $62.56 \%$ & 50 & $15: 00: 00.0000$ & $18: 00.0000$ & 0.0000 \\
\hline Trhanie & $31.28 \%$ & 50 & $7: 30: 00.0000$ & $9: 00.0000$ & 0.0000 \\
\hline Zmiesavanie & $38.23 \%$ & 50 & $9: 10: 00.0000$ & $11: 00.0000$ & 0.0000 \\
\hline Mykanie & $45.18 \%$ & 50 & $10: 50: 00.0000$ & $13: 00.0000$ & 0.0000 \\
\hline Havijanie & $31.28 \%$ & 50 & $7: 30: 00.0000$ & $9: 00.0000$ & 0.0000 \\
\hline Source & $0.00 \%$ & 0 & 0.0000 & 0.0000 & 0.0000 \\
\hline Drain & $0.00 \%$ & 50 & 0.0000 & 0.0000 & 0.0000 \\
\hline Line & $100.00 \%$ & $123: 58: 37.6667$ & $23: 58: 37.6667$ & 0.0000 \\
\hline Line2 & $100.00 \%$ & $123: 58: 37.666723: 58: 37.6667$ & 0.0000 \\
\hline Line1 & $100.00 \%$ & $123: 58: 37.666723: 58: 37.6667$ & 0.0000 \\
\hline Line3 & $100.00 \%$ & $123: 58: 37.6667$ & $23: 58: 37.6667$ & 0.0000 \\
\hline Line4 & $100.00 \%$ & $123: 58: 37.6667$ & $23: 58: 37.6667$ & 0.0000 \\
\hline Odstranovanie & $93.84 \%$ & 50 & $22: 30: 00.0000$ & $27: 00.0000$ & 0.0000 \\
\hline Buffer & $0.00 \%$ & 0 & 0.0000 & 0.0000 & 0.0000 \\
\hline Buffer1 & $0.00 \%$ & 0 & 0.0000 & 0.0000 & 0.0000 \\
\hline Buffer2 & $0.00 \%$ & 0 & 0.0000 & 0.0000 & 0.0000 \\
\hline Lisovanie & $24.33 \%$ & 50 & $5: 50: 00.0000$ & $7: 00.0000$ & 0.0000 \\
\hline
\end{tabular}

Figure 6. The output from simulation - Tecnomatix Plant 
Via Witness simulation tool, it was created the same model in a similar way as in the case of creating Tecnomatix Plant entities.
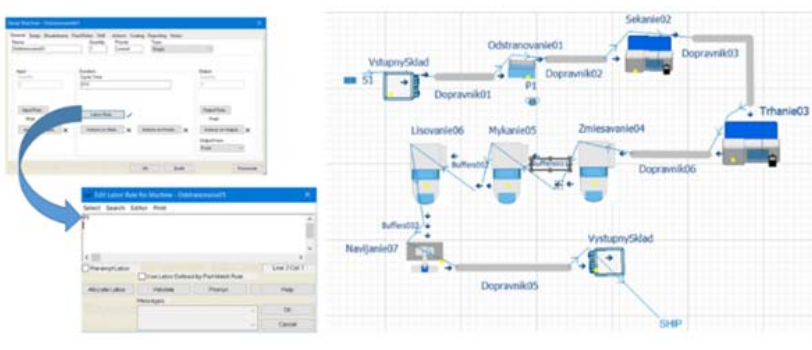

Figure 7. Entity creation - Witness

Statistical data assessment using tabular reports brings a higher degree of reliability, as the data displayed graphically produces inaccurate results, which can lead to erroneous decision-making processes.

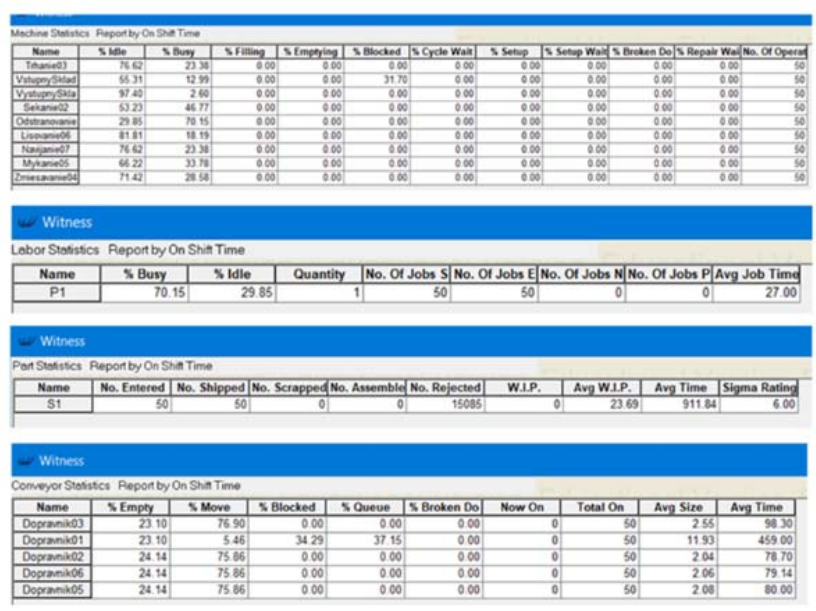

Figure 8. The output from simulation - Witness

\section{Conclusion}

Simulation is a part of everyday life in manufacturing companies. With these tools, it is possible to evaluate different line production, check ongoing strategies, and verify process synchronization. The presented paper provides alternative approaches to the rationalization of production processes using simulation methods by implementing comparative rationalization. In both simulation tools, it is necessary to create entities using a powerful object-oriented architecture and modelling functions that allow us to create and maintain very complex systems, including advanced control mechanisms. The individual components are selected from richly equipped libraries of application objects, which are constantly expanding in both programs. Subsequently, 2D data is generated using visualization tools in a $3 \mathrm{D}$ interface, which allows us to present the entire system concept in a virtual, interactive environment. Based on the results of comparative rationalization, it can be stated that the complexity of simulation sets is at a high level, while the complexity in the Tecnomatix Plant program is eliminated by the complexity of tools, but at the expense of the accuracy of the compiled model. Simulation tools form an integral part of internal and external supply chains, production resources and business processes, with the possibility of analysing the effects of various production changes, making simulations a constantly open issue for the implementation of research in science and technology.

\section{Acknowledgements}

This article was supported by the research grant KEGA 030TUKE-4/2018 and VEGA 1/0080/20.

\section{References}

[1]. Orlovský, I., Hatala, M., \& Janák, M. (2010). Creation of simulation model of ceramic granulate production in spraying kiln. Technical Gazette, 17(4), 419-423.

[2]. Hatala, M., Zajac, J., Čep, R., \& Orlovský, I. (2012). Research of the technological parameters importance for plasma arc thermal cutting. In Applied Mechanics and Materials (Vol. 110, pp. 3742-3749). Trans Tech Publications Ltd.

[3]. Hutyrová, Z., Harničarová, M., Zajac, J., Valíček, J., \& Mihok, J. (2014). Experimental study of surface roughness of wood plastic composites after turning. In Advanced Materials Research (Vol. 856, pp. 108112). Trans Tech Publications Ltd.

[4]. Mourtzis, D., Doukas, M., \& Bernidaki, D. (2014). Simulation in manufacturing: Review and challenges. Procedia Cirp, 25, 213-229.

[5]. Duplakova, D., Duplak, J., Mital, D., Soltes, P., \& Sukic, E. (2020). Analysis of approaches to the material flow in the production process with the use of simulation. STED Journal, 2 (1), 36-44.

[6]. Bacon, B., \& Pennec, S. (2009). Microsimulation, Macrosimulation: model validation, linkage and alignment. In 2nd General Conference of the International Microsimulation Association'Microsimulation: Bridging Data and Policy', Ottawa, Canada.

[7]. Flimel, M. (2019). Optimisation of the design of an acoustic screen at a workplace. Akustika, 31, 13-18.

[8]. Kliment, M., Trebuna, P., Pekarcikova, M., Straka, M., Trojan, J., \& Duda, R. (2020). Production Efficiency Evaluation And Products'quality Improvement Using Simulation. International Journal of Simulation Modelling (IJSIMM), 19(3).

[9]. Kočiško, M., Novák-Marcinčin, J., Baron, P., \& Dobránsky, J. (2012). Utilization of progressive simulation software for optimization of production systems in the area of small and medium companies. Tehnički vjesnik, 19(4), 983-986.

[10]. Knapčíková, L., Behúnová, A., \& Behún, M. (2020). Using a discrete event simulation as an effective method applied in the production of recycled material. Advances in Production Engineering \& Management, 15(4), 431-440.

[11]. Al-Aomar, R., Williams, E. J., \& Ulgen, O. M. (2015). Process simulation using witness. John Wiley \& Sons. 